open 2 access

\title{
Utility of Combined Echocardiography and Lung Ultrasound for Coronavirus Disease-19 Intensive Care Unit Patients: Case Series
}

\author{
Marijan Bosevski ${ }^{1 \star}$, Filip Janusevski ${ }^{1}$, Kosta Kapsarov ${ }^{2}$ \\ ${ }^{1}$ University Cardiology Clinic, Faculty of Medicine, Skopje, Republic of Macedonia; ${ }^{2}$ University Clinic for Infective Diseases, \\ Skopje, Republic of Macedonia
}

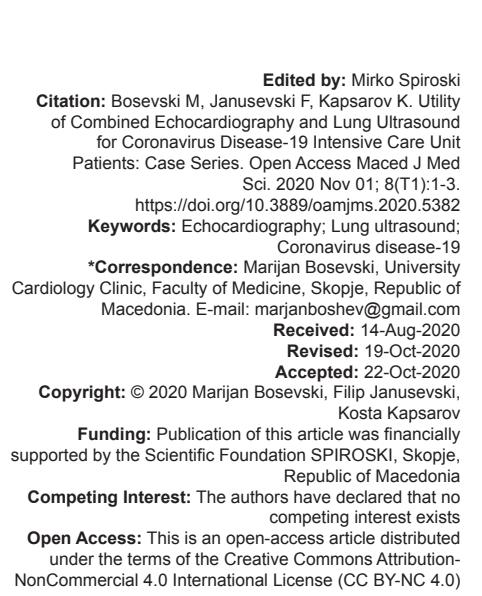

Abstract

BACKGROUND: A little evidence existed for ultrasound evaluation of coronavirus disease (COVID)-19 patients.

AIM: We aimed to present combined transthoracic echocardiography and lung ultrasound in 17 COVID-19 patients in the intensive care unit (ICU).

METHODS: Patients were on age $57+14$ years, 9 on mechanical ventilation and 8 on oxygen support, with average 1.2 comorbidities per patient. Ultrasound was performed by a single experienced sonographer and an assistant.

RESULTS: Impaired left ventricular ejection fraction (EF) was found in 2 patients (pts) of them (11.8\%) and diastolic dysfunction in $7(41.2 \%)$, which was significantly higher in those ones with comorbidities. In 2 pts $(11.8 \%)$, the presence of pulmonary hypertension with enlarged right ventricle was found. Later one pulmonary thromboembolism was confirmed in them with computed tomography angio. B-lines were found in 8 pts $(47.1 \%)$, finding that was significantly higher in pts on mechanical ventilation, but not in relation with decreased EF. In one pt $(0.6 \%)$, pleura effusion was found, but in none of them lung consolidation.

CONCLUSIONS: Our findings revealed that combined echocardiography and lung ultrasound in COVID-19 ICU pts have been an accurate method for diagnosing right and left ventricular function and should be a useful one for guiding of their treatment and prognosis.

\section{Introduction}

Nowadays, cardiopulmonary injury has been recognized in patients with coronavirus (CoV) disease (COVID)-19, the clinical disease state caused by infection with the novel CoV, severe acute respiratory syndrome (SARS)-CoV-2. While originally believed to be a primary lower respiratory infection, as more cases are identified, treated, and examined, thrombotic complications are being identified as a significant driver in morbidity and mortality associated with the disease. Elevated D-dimer levels and troponin values have been identified as being associated with increased mortality [1]. Yet, D-dimer and troponin could not prove a valuable tool to identify patients who are likely to have poorer outcomes and allow for prophylactic treatment and monitoring of secondary complications [2].

The first case that was confirmed in Republic of Macedonia by polymerase chain reaction (PCR) for SARS-CoV-2 virus in Institute for Public Health was on $26^{\text {th }}$ of February 2020, and the first death was reported in Clinic of Infective Diseases on $25^{\text {th }}$ of March same year. The case fatality rate for COVID-19 pts for Republic of Macedonia is 4.1 .
Transthoracic echocardiography (TTE) is a basis for heart imaging, diagnosis of left and right ventricle overload, heart failure, but also for hemodynamic monitoring of these pts. European Association for Cardiovascular Imaging postulated consensus document for using a TTE in patients with COVID-19 [3].

However, a little evidence existed for echocardiographic evaluation of COVID-19 patients, combining it with a lung ultrasound in the intensive care unit (ICU) [4].

In this paper, we present a case series of 17 patients COVID-19, evaluated with combined echocardiography and lung ultrasound.

\section{Methods}

The group consisted of COVID-19 patients ( $n=17$ ), hospitalized in the ICU of Clinic for Infective Disease in Skopje, with moderate and severe clinical symptoms. All tested positive for SARS-CoV-2 RNA through PCR in the Institute for Public Health. 
Ultrasound was performed by a single experienced physician and an assistant. Standard transthoracic echocardiographic evaluation was performed in all of pts. Bilateral lung ultrasound was done at all. GE Vivid T8 device was used.

\section{Results}

Patients were aged $57+14$ years. Nine of them were on mechanical ventilation and 8 on oxygen support. Three of them died during hospitalization.

There were average 1.2 comorbidities per patient. Most frequent comorbidities were arterial hypertension $(64.7 \%)$ and diabetes (58.9\%). There were histories of cerebrovascular diseases in $1 \mathrm{pt}$, chronic pulmonary disease (chronic obstructive pulmonary disease and asthma) in 3 pts, and chronic kidney diseases in 2 pts. Malignant diseases, immunodeficiency disorders, were not noticed in the study population. At the admittance, most of the pts presented clinical symptoms of cough (9 pts), dyspnea (13 pts), and fever (7 pts).

In a study population mean value of D-dimmer $(1300 \mathrm{ng} / \mathrm{ml}+900), \operatorname{CRP}(49 \mathrm{mg} / \mathrm{L}+13)$, and white blood cell $\left(19 \times 10^{9}+5\right)$ was found. Antiviral therapy was administered in 13 pts and antibiotic in 15 of them.

Impaired left ventricular ejection fraction (EF) was found in 2 pts of them (11.8\%), and diastolic dysfunction in 7 (41.2\%), which was significantly higher in those ones with comorbidities $(p<0.05)$.

In 2 pts $(11.8 \%)$, the presence of pulmonary hypertension with enlarged right ventricle was found (Figure 1). Later one pulmonary thromboembolism was confirmed in them with computed tomography (CT) angiography.

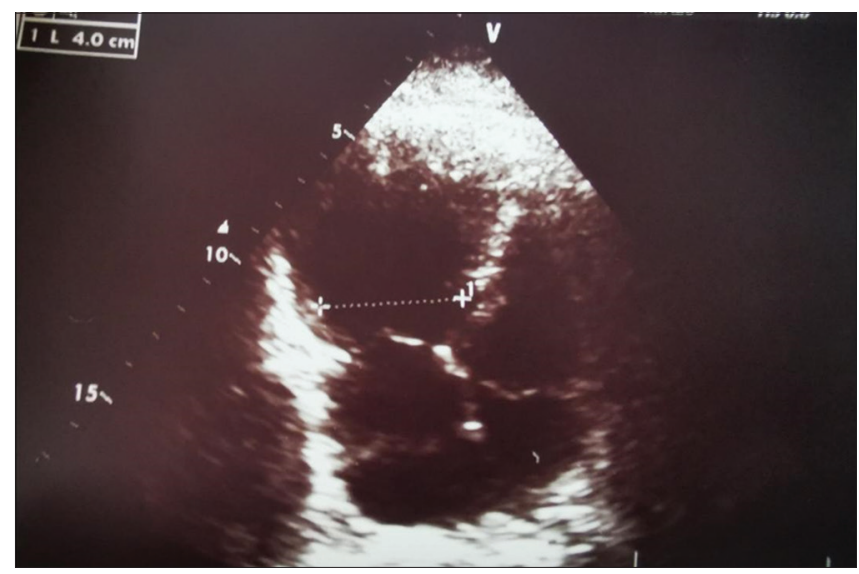

Figure 1: Increased diameter of the right ventricle

B-lines were found in 8 pts $(47.1 \%)$, finding that was significantly higher in pts on mechanical ventilation, but not in relation with decreased EF. That was shown in Figure 2.

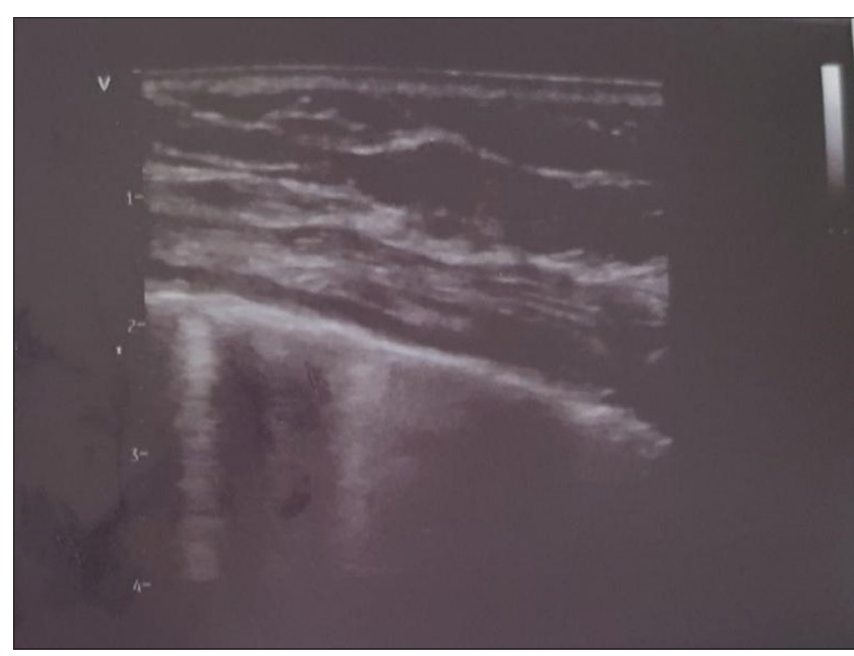

Figure 2: B-lines in lung parenchyma

In one pt $(0.6 \%)$, pleural effusion was found. In 9 pts (52.9\%), irregular thickened pleural line was found (Figure 3 ). In none of them was found a lung consolidation.

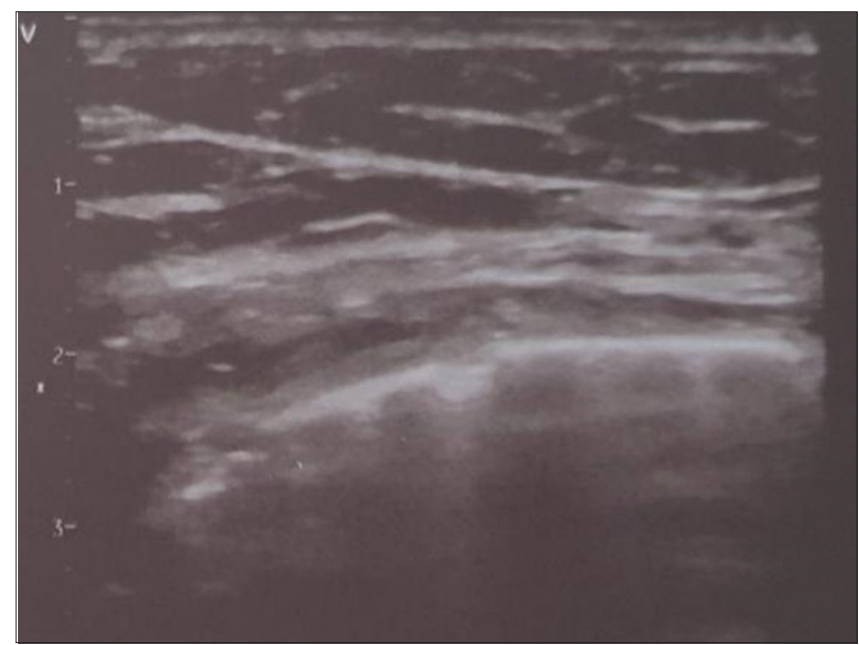

Figure 3: Irregular thickened pleural line

\section{Discussion}

We found LV dysfunction in $11.8 \%$ of pts. It is not a very common condition in COVID-19 pts [5]. However, diastolic dysfunction is found in $42.3 \%$ of pts. Similar results were found in a study by Yishay Szekely [3]. Analysis of COVID-19 pts by Edler in International data found heart failure as a reason for death in one-third of them [6].

$\mathrm{RV}$ dysfunction is common findings in these pts. We found it in only 2 of pts. This is due to pulmonary thromboembolism (found in $11.8 \%$ of our pts), pneumonia, increase pulmonary vascular resistance [7]. Finding the reason for $\mathrm{RV}$ overloads sometimes in impossible if CT angio is not done. However is it very useful for administration for therapy. 
Definition of pulmonary edema and interstitial lung disease is very controversial. One of the conditions that confirm interstitiopathy in the presence of $B$ lines is normal LVEF. Distribution of B lines (no homogeneous) and fragmentation or irregularity of pleural line confirms lung disease. Lung ultrasound could potentially distinguish two types of disturbances. It has high sensitivity and low specificity to diagnose lung disease and pulmonary edema. It is more specific if the probe is used in lateral and posterior parts of the lungs. These could be increased by clinical settings of pts [8]. We found $B$ lines in almost in half of the pts.

Focused echocardiography and lung ultrasound were also used for guiding treatment of pts with heart failure when administered serial [9].

There was a lack of ECG trace for echo images. X-ray was used in 3 pts and CT only in one pt. Non-randomization and non-homogeneity was also a study limitation.

This small case study group that we described allows identification and possible prognostication of CIVID-19 pts. Future larger studies are needed [10].

\section{Conclusion}

Our findings reveal that combined echocardiography and lung ultrasound in COVID-19 ICU pts has been an accurate method for diagnosing right and left ventricular function and can be a useful one for guiding of their treatment and prognosis.

\section{References}

1. Bikdeli B, Madhavan MV, Jimenez D, Chuich $T$, Dreyfus I, Driggin E, et al. COVID-19 and thrombotic or thromboembolic disease: Implications for prevention, antithrombotic therapy, and follow-up: JACC state-ofthe-art review. J Am Coll Cardiol. 2020;75(23):2950-73. PMid:32311448

2. Di Micco P, Di Micco G, Russo V, Poggiano MR, Salzano C, Bosevski M, et al. Blood targets of adjuvant drugs agaist Covid19. J Blood Med. 2020;11:237-41. PMid:32694923

3. Skulstad H, Cosyns B, Popescu BA, Galderisi M, Salvo GD, Donal E, et al. COVID-19 pandemic and cardiac imaging: EACVI recommendations on precautions, indications, prioritization, and protection for patients and healthcare personnel. Eur Heart J Cardiovasc Imaging. 2020;21(6):592-8. $\quad$ https://doi.org/10.1093/ehjci/jeaa072 PMid:32242891

4. Mitevska I, Poposka L. Coronavirus disease-19 and cardiovascular disease. Open Access Maced J Med Sci. 2020;8(T1):39-44. https://doi.org/10.3889/oamjms.2020.4804

5. Szekely $\mathrm{Y}$, Lichter $\mathrm{Y}$, Taieb $\mathrm{P}$, Banai A, Hochstadt $\mathrm{A}$, Merdler I, et al. The spectrum of cardiac manifestations in coronavirus disease 2019 (COVID-19) a systematic echocardiographic study. Circulation. 2020;142(4):34253. https://doi.org/10.1161/circulationaha.120.047971 PMid:32469253

6. Edler C, Schröder AS, Aepfelbacher M, Fitzek A, Heinemann A, Heinrich F, et al. Dying with SARS-CoV-2 infection-an autopsy study of the first consecutive 80 cases in Hamburg, Germany. Int J Legal Med. 2020;134(4):127584. https://doi.org/10.1007/s00414-020-02317-w PMid:32500199

7. Ackermann $M$, Verleden SE, Kuehnel $M$, Haverich $A$, Welte $\mathrm{T}$, Laenger $\mathrm{F}$, et al. Pulmonary vascular endothelialitis, thrombosis, and angiogenesis in Covid-19. N Engl J Med. 2020;383(2):120-8. https://doi.org/10.1056/nejmoa2015432 PMid:32437596

8. Gargani L, Soliman-Aboumarie H, Volpicelli G, Corradi F, Pastore MC, Cameli M. Why, when, and how to use lung ultrasound during the COVID-19 pandemic: Enthusiasm and caution. Eur Heart J Cardiovasc Imaging. 2020;21(9):941-8. https://doi.org/10.1093/ehjci/jeaa163 PMid:32515793

9. Öhman J, Harjola VP, Karjalainen P, Lassus J. Focused echocardiography and lung ultrasound protocol for guiding treatment in acute heart failure. ESC Heart Fail. 2018;5(1):120-8. https://doi.org/10.1002/ehf2.12208 PMid:28960894

10. Tarakji B, Alali FM, Alenzi A, Nassani MZ. Systematic review with no meta-analysis of coronavirus COVID-19. Open Access Maced J Med Sci. 2020;8(T1):108-11. https://doi.org/10.3889/ oamjms. 2020.4873 